\title{
Kali Argyriadis, Stefania Capone (Dir.), La religion des orisha. Un champ social transnational en pleine recomposition
}

Index, table des encarts, cartes et schéma, tables des illustrations

Paris, Hermann, 2011, 345 p.

\section{Elena Zapponi}

\section{(2) OpenEdition}

\section{Journals}

Édition électronique

URL : http://journals.openedition.org/assr/25377

DOI : $10.4000 /$ assr.25377

ISSN : $1777-5825$

Éditeur

Éditions de l'EHESS

Édition imprimée

Date de publication : 30 décembre 2013

Pagination : 128

ISSN : 0335-5985

Référence électronique

Elena Zapponi, « Kali Argyriadis, Stefania Capone (Dir.), La religion des orisha. Un champ social transnational en pleine recomposition », Archives de sciences sociales des religions [En ligne], 164 |

2013, mis en ligne le 18 février 2014, consulté le 21 septembre 2020. URL : http://

journals.openedition.org/assr/25377 ; DOI : https://doi.org/10.4000/assr.25377

Ce document a été généré automatiquement le 21 septembre 2020.

(C) Archives de sciences sociales des religions 


\section{Kali Argyriadis, Stefania Capone (Dir.), La religion des orisha. Un champ social transnational en pleine recomposition}

Index, table des encarts, cartes et schéma, tables des illustrations Paris, Hermann, 2011, 345 p.

Elena Zapponi

\section{RÉFÉRENCE}

Kali Argyriadis, Stefania Capone (Dir.), La religion des orisha. Un champ social transnational en pleine recomposition, Index, table des encarts, cartes et schéma, tables des illustrations, Paris, Hermann, 2011, 345 p. 
1 Cet ouvrage, né sous la direction de deux chercheuses spécialistes des études afroaméricaines - Stefania Capone, dont les recherches portent sur la transnationalisation et la réinvention de l'africanité (on rappelle Les Yoruba du Nouveau Monde: religion, ethnicité et nationalisme noir aux États-Unis, Paris, Karthala, 2005) et Kali Argyriadis, qui a étudié longtemps la santería cubaine et notamment publié La religion à La Havane. Actualité des représentations et des pratiques cultuelles havanaises (Paris, Éditions des Archives contemporaines, 1999) analyse la récente diffusion d'un écoumène yoruba transnationale. Après des études sur les pratiques religieuses afro-américaines, observées au Brésil et à Cuba, K. Argyriadis et S. Capone s'attachent à déceler les adaptations et

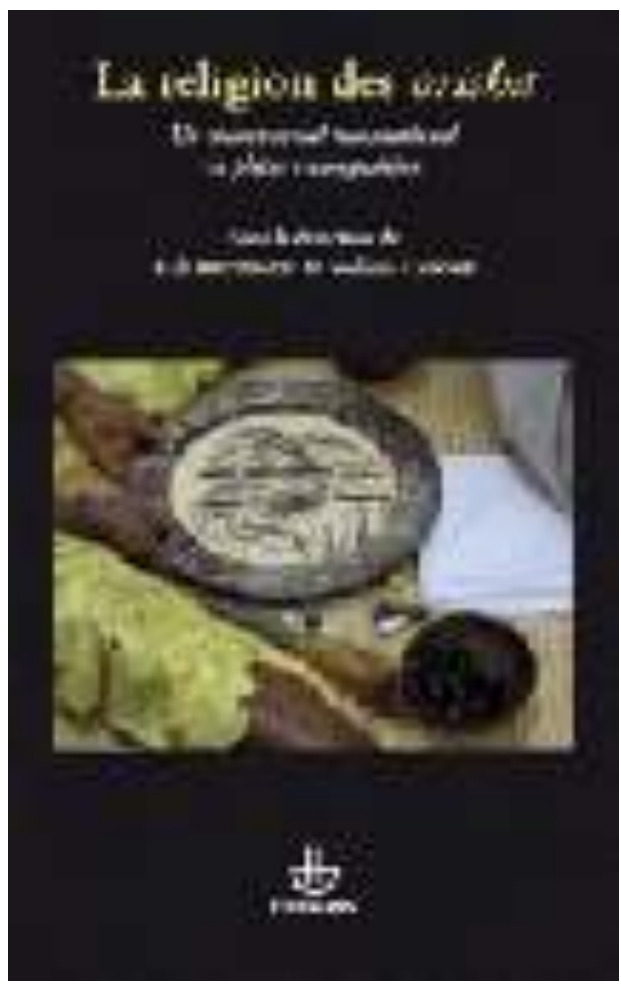
réappropriations qui se produisent lors de la relocalisation de ces religions. Centrale, dans ce processus, est la réinvention de la notion d'ailleurs, une Afrique, terre des origines, allà souvent plus mythique que réel. L'expression la religion des orisha, qui donne le titre à l'ouvrage, indique l'évolution qui s'affirme dans le champ religieux afro-américain; bien que l'ensemble de ces religions ne consiste pas exclusivement dans des pratiques yoruba, les orisha, dieux d'origine yoruba, s'imposent dans les forums religieux internationaux. Le choix de cette dénomination englobante permet d'estomper toute spécificité locale et historique pour souligner une africanité commune et affirmer une religion universelle, une World religion, promue par institutions religieuses et séculières transcendant les particularismes régionaux et locaux. Comme le soulignent les auteurs, ce rapprochement d'une pureté africaine fondatrice permet d'introduire le global dans le local. Mais cette idée d'une religion des orisha, liée à la préexistence de l'Afrique comme communauté imaginée, "trope centrale qui alimente l'imagination des afro-descendants » n'est pas mobilisée de la même manière par les acteurs sociaux: les différents contributeurs de l'ouvrage illustrent comment l'utopie de la référence partagée "Afrique " correspond à un univers religieux pluriel, travaillé par l'opposition entre différents régimes de vérité. Le poids des imaginaires nationaux demeure important : les identités nationales ne sont pas effacées, mais redéployées engendrant des identités stratifiées.

2 Le livre est organisé en huit chapitres, chacun centré sur le processus de transnationalisation de la "religion des orisha» en différents continents, voire l'Amérique latine (Mexique, Argentine), l'Europe (Espagne, Portugal) et les États-Unis.

3 Un solide chapitre par K. Argyriadis et S. Capone, s'appuyant sur une bibliographie riche et multifocalisée, ouvre le livre : la formation du champ social transnational, les réseaux transnationaux, les problèmes d'adaptation qui caractérisent le processus de traduction culturelle y sont analysés. 
4 Dans le chapitre suivant, Stefania Capone approfondit les réarrangements rituels au sein de la religion des orisha en considérant les figures du pai-de-santo et du babalao, le premier représentant le père du secret dans le candomblé brésilien, le deuxième, spécialiste de la divination d'Ifá, centrale dans la santería cubaine. L'enjeu de l'analyse est de souligner l'interconnexion croissante dans les pratiques religieuses de la diaspora entre santería et candomblé. L'auteur considère ici les "malentendus productifs » qui naissent au cours de la réadaptation locale de la religion : ces « presque rien » renvoyant au « nœud intime de l'identité religieuse » sont des écarts différentiels qui constituent des formes de stratégies interpersonnelles et interculturelles (p. 82 et suiv.).

5 Maia Guillot contribue par le troisième chapitre à une réflexion sur l'adaptation du candomblé et de l'umbanda au champ religieux portugais. L'implantation locale des cultes afro-brésiliens permet un renforcement des croyances populaires en leur offrant la marque institutionnelle niée par le catholicisme. L'auteur montre bien ce cumul des pratiques, le glissement d'un univers religieux à un autre, l'indigénisation des cultes et des esprits et la logique des réarrangements des croyances vis-à-vis d'une légitimation rituelle et institutionnelle.

6 Nahayeilli B. Juarèz Huet, auteur du quatrième chapitre, «Les processus de relocalisation de la santería au Mexique : narcosataniques, sorciers et santecas " considère les nouveaux usages et la resémantisation de la santería dans la ville de Mexico. Dans l'analyse, la notion de "complémentarité » est centrale; la santería est identifiée comme une pratique qui offre une alternative thérapeutique; l'adepte ne fait pas une tabula rasa de ses croyances antérieures, mais il met en œuvre la construction des « ponts sémantiques » en accord avec sa trajectoire spirituelle.

7 Le cinquième chapitre, par Kali Argyriadis « Relocalisation dans le Port de Veracruz : le marché, espace restreint de légitimité» est une analyse passionnante de la transnationalisation de la santería de Cuba à Veracruz, port d'entrée du Mexique, à partir d'une ethnographie du marché le plus important de la ville, lieu de commerce de produits, objets, images magiques ou «sorciers ». Les modalités de relocalisation de la santería sont également analysées en s'attardant sur un exemple : l'assimilation de l' oricha de la mer, Yemayà, avec l'un des avatars de la Santa Muerte. Enfin, le poids de l'hégémonie catholique et les contraintes que ce modèle ecclésial impose à la réinterprétation locale de la santería sont considérés.

8 Le septième chapitre, par Lorraine Karnoouh, étudie la diffusion des pratiques New Age à La Havane et leur adoption dans le contexte cultuel local de la religión, système composé par le catholicisme et les différentes expressions religieuses d'origine africaine et le spiritisme. Pour illustrer ce paysage, trois itinéraires de chercheurs spirituels dessinant différents types de trajectoires religieuses sont présentés. Dans cette contribution aussi, la notion d'« usage complémentaire des pratiques» et de nouvel ancrage sur des "ponts cognitifs» qui permettent des correspondances sémantique ressort comme centrale.

9 Suit la contribution de Caterina Pasqualino, «Entre féerie et macabre, les religions afro-cubaines en Espagne " dont on apprécie la qualité du travail de terrain. Selon l'auteur, la pratique des religions afro-cubaines et l'adhésion des nombreux catholiques à ces cultes annoncent le succès d'une "religion de service ", évoquant le pragmatisme déjà présent dans le contexte religieux d'origine. L'auteur explique le recours à la 
santería et au palo-monte comme un couple de cultes qui trouve une correspondance dans le catholicisme populaire espagnol et dans la pratique de la sorcellerie.

10 Le succès de la relocalisation de ces religions tient d'une part à leur côté thérapeutique visant à récupérer l'énergie de l'adepte, de l'autre à leur caractère de "religions de proximité ", systèmes capables de réactualiser le dialogue avec des divinités domestiques adaptées à l'individu et à ses problèmes quotidiens. En outre, un facteur qui favorise la relocalisation des cultes afro-cubains en Espagne est identifié dans l'art somptuaire de la Santería Qui Révèle Une Iconologie Familière A L'esthétique Catholique Baroque.

11 Le huitième et dernier chapitre par Alejandro Frigerio s'attarde sur l'expansion de l'umbanda et du batuque dans le Cône sud (Argentine et Uruguay) : l'article met l'accent sur une transnationalisation religieuse qui se déroule par des réseaux multiples et interconnectés sans impliquer une forte présence d'immigrés ou une intention d'entreprise missionnaire. L'auteur analyse les processus «d'alignement des cadres interprétatifs ", considéré tant au niveau micro de la conversion et de la pratique personnelle qu'au niveau macro de la légitimation sociale.

Ce livre fait preuve du dynamisme des religions étudiées dont la pratique aujourd'hui déborde largement de l'aire afro-américaine. L'ouvrage, enrichi par des photos, dont les chercheurs sont souvent les auteurs, a le mérite de s'appuyer sur l'exercice d'une ethnographie multisituée et une bibliographie bien mise à jour. 